\title{
FOSTERING LANGUAGE LEARNER AUTONOMY THROUGH INTERDEPENDENCE: THE POWER OF WIKIS
}

\author{
Dr. Shirin SADAGHIAN \\ ORCID: 0000-0003-1405-5363 \\ Alzahra University \\ Tehran, IRAN \\ Dr. Susan MARANDI \\ ORCID: 0000-0001-9852-1880 \\ Department of Languages \\ Alzahra University \\ Tehran, IRAN
}

Received: 06/04/2020 Accepted: 28/07/2020

\begin{abstract}
The present study reports on a collaborative writing project initiated and completed by 18 Iranian English language learners enrolled in an online writing course. Using a wiki as the core element of the project, the aim of the course was fostering learner autonomy in online settings based on the collaborative autonomous language learning framework proposed by Kessler and Bikowski (2010). The outcome of collaborative writing project was a text created in a wiki, which was manually analyzed from the very beginning of writing to the final revisions and reflections to find autonomous alterations made by student writers. The findings of the study revealed student-writers' autonomous contributions in the form of alterations to the text which were accomplished interdependently with peers through alterations such as commenting as an instance of scaffolding to reach a shared goal. Other types of autonomous alterations such as adding new information; deleting existing information; correction of information; clarification; synthesis; and reflection were observed in the final product. Frequent occurrence of peer correction with regard to content and form was a discriminating finding of the current study. Also, despite the initial goal which was completion of the project exclusively by learners, teacher intervention was witnessed throughout the process. To study the role of teacher in depth, a semi-structured interview about the roles of a teacher in a collaborative autonomous learning was conducted. The data from the interview went through a manual thematic analysis to find the themes related to the learners' perceptions of teacher's roles. The findings revealed a need for a teacher as a facilitator and resource, which highlighted students' demands for motivation and content knowledge from teacher in an autonomous contribution to completing a collaborative project.
\end{abstract}

Keywords: Learner autonomy, collaborative writing, wiki, online education, interdependence.

\section{INTRODUCTION}

One of the affordances of technology for language learners is the creation of opportunities to use language in collaborative authentic contexts. Such contexts are assumed to increase learners' autonomy by developing a "capacity for reflection and analysis, which is central to the development of learner autonomy" (Little, 1996, p. 210).

However, the availability of technology alone does not lead toward independence from teacher and pedagogy. Benson (2001) points out that a number of researchers have used the term independence interchangeably with autonomy, whereas, equating the two concepts ignores the social character of learning. Such a definition loses sight of the fact that interdependence lies at the heart of the concept of autonomy. Little (1996) believes that social interaction is at the center of the concept of autonomy and the development of capacity for reflection "depends on the internalization of a capacity to participate fully and critically in social interactions" (p. 210). Kohonen (1992), cited in Benson (2001), argues that "autonomy entails the notion of 
interdependence which means being responsible for one's own conduct in the social context" (p. 14). What interdependence entails here is being responsible for one's own conduct in the social context that is being able to cooperate with others and solve conflicts in constructive ways (Kohonen, 1992, p.19)

With the advent of technology, social interaction is extended to include an additional virtual dimension. Schwienhorst (2008) claims that technology is capable of assisting a learner-autonomy-based pedagogy that supports reflection, interaction, experimentation, and participation of learners. In addition, the growing role of technology has changed the essence of learner autonomy to interaction and interdependence rather than isolation and independence (Healey, 2007; Schwienhorst, 2003).

The current study focuses on a collaborative writing project completed using an educational wiki to address the following research questions:

1. How do Iranian language learners demonstrate autonomy in a collaborative wiki-based writing project?

2. How does a degree of teacher intervention affect EFL learners' autonomous collaborative behavior?

\section{LITERATURE REVIEW}

\section{Language Learner Autonomy}

Increasing levels of learner autonomy has been an important educational goal during recent decades. This entails detachment from one's own learning, development of linguistic and metalinguistic awareness, and creating an ability to reflect on one's own learning procedure. Apart from being aware of their own learning, autonomous learners also need to practice collaboration with teacher, learners, and native speakers or more experienced peers (Schwienhorst, 2012) in order to take control of their learning in various learning situations.

The role of a teacher can also vary in autonomous learning based on her/his interaction with learners. According to Voller (1997), a teacher can take on three different roles as a facilitator, counsellor, and resource. The language teacher may act as a facilitator who initiates and supports decision-making processes, a counselor who responds to the ongoing needs of individuals, and a resource who makes his or her knowledge and expertise available to the learners in times of need.

In the same vein, Littlewood (1996) asserts that in an autonomous learning setting, learners should take on different roles to practice complete control over their learning. In his framework for promoting autonomy among language learners, Littlewood (1996) assigns three roles to an autonomous individual, namely that of communicator, learner, and person.

Autonomy as a communicator depends on (a) the ability to use the language creatively, and (b) the ability to use appropriate strategies for communicating meanings in specific situation. Autonomy as a learner depends on (a) the ability to engage in independent work (e.g. self-directed learning), and (b) the ability to use appropriate strategies, both inside and outside classroom. Finally, autonomy as a person depends (in the foreign language learning context) on (a) the ability to express personal meanings, and (b) the ability to create personal learning contexts, e.g. through interacting outside the classroom. (p. 431)

At the very heart of Littlewood's (1996) autonomy framework, there are two major components, namely "ability" and "willingness," which are the prerequisites for all types of learnings. Ability includes both "knowledge" about various choices offered to the learner and the "skills" for implementing those choices, whereas "willingness" involves "motivation and the confidence to take responsibility" for one's decisions (p. 428). Figure 1 shows the elements of the framework in detail. 


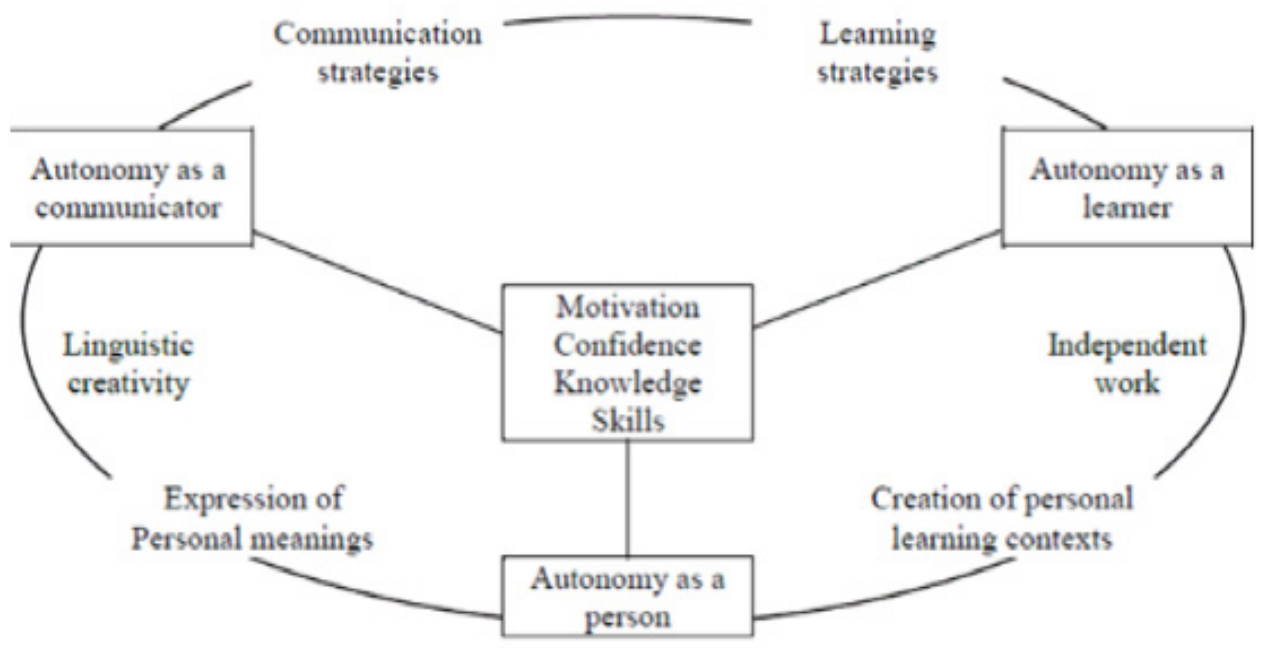

Figure 1. A Framework for developing autonomy in foreign language learning (Adopted from Littlewood, 1996, p.432).

Littlewood $(1996,1997)$ suggests the autonomous approach be used as a teaching methodology that focuses on linking classroom learning to learning beyond the classroom. However, despite the merits of Littlewood's framework, it does not recognize the importance of interdependence, which is vital to the interaction in which learning lies (Little, 1995(. To compensate for this shortcoming, Kessler and Bikowski (2010) add a new dimension to acknowledge the importance of students' developing collaborative autonomous language learning abilities from what Levy and Hubbard (2005) call a "CALL-centered viewpoint." From a CALLcentered point of view, the computer is not a neutral delivery system and the interaction among computer, learner, peer, teacher, and the learning material altogether, leads toward learning goals. The notion of interdependence is clearly indicated in Kessler and Bikowski's (2010) framework through the mediating role of the computer. According to Kessler and Bikowski (2010), the framework encompasses the responsibility of collaborative autonomous language learners in CALL-focused settings by adding interdependence to autonomy as a learner.

\section{Collaborative Autonomous}

\section{Language Learner}

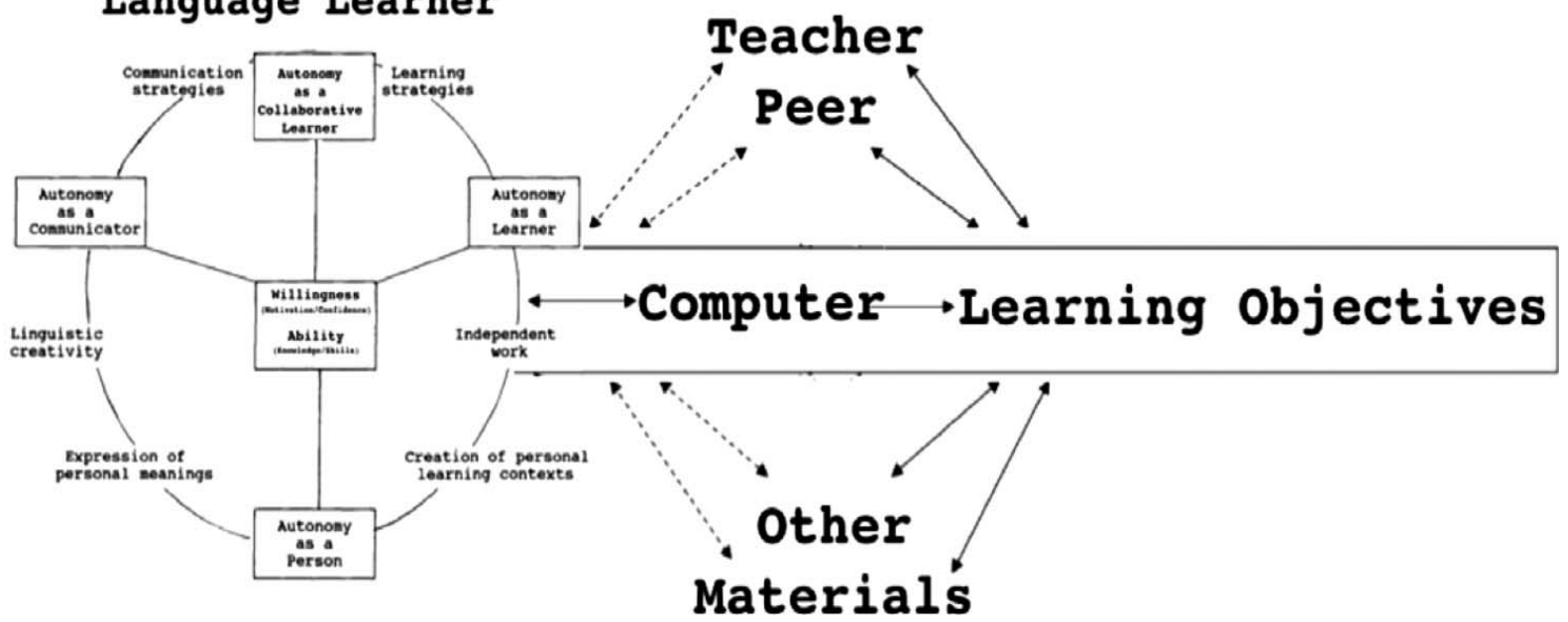

Figure 2. An expanded framework for developing collaborative autonomous language learning abilities in computer mediated contexts (Adopted from Kessler \& Bikowski, 2010, p. 55). 
In the above framework, Kessler and Bikowski (2010) introduce the features of collaborative autonomous learners, which include:

(1) the ability to use language to independently contribute personal meanings as a collaborative member of a group,

(2) the ability to use appropriate strategies for communicating as a collaborative member of a group,

(3) the willingness to demonstrate these abilities within the group. (p. 49)

Kessler and Bikowski's (2010) study is not the first to look at the concept of learner autonomy from a CALL-centered point of view. The importance of autonomy in online courses has led many researchers (e.g. Warschauer, Turbee \& Roberts, 1996; Schwienhorst, 2003) to explore the relationship among CALL, educational technologies, and learner autonomy and to investigate how the new technologies require and at the same time assist learner autonomy.

Schwienhorst (2003), for example, devotes a chapter of his book to explain how through the tandem learning technique, he attempts to foster learner autonomy in a MUD Object Oriented (MOO) environment. "Tandem learning involves learners of complementary L1-L2 combinations learning a new language through playing the roles of L2 learner and L1 expert" (p. 431). Schwienhorst believes that the combination of pedagogy and technology supports learner autonomy through helping learners to reflect on their own learning planning, monitoring and evaluating the learning process. Moreover, the affordances of technology engage learners in different types of communications, similar to real life situations. Finally, the combined pedagogy/technology frameworks provide learners with the opportunity to experiment with and participate in the process of language learning and accept the responsibility to co-design and customize their learning environments.

Obviously, the mere addition of technology without the intervention of pedagogy would not serve the purposes of autonomy (Levy, 1997) yet, there are many ways through which CALL can enable the application of autonomy training. For instance, Reinder and Hubbard (2012) propose the free and ubiquitous access to resources as an advantage of CALL through which one can overcome the practical and political limitations on autonomy. Moreover, the authenticity of online materials (Reinder and Hubbard, 2012) is seen as an important plus for the development of learner autonomy (Benson, 2007).

\section{Collaborative Writing}

Collaborative writing, which involves multiple authors in producing a written work, is considered as a useful method for practicing process writing (Chao \& Lo, 2011). In essence, collaborative writing is a collaborative learning process. According to Vygotsky (1978), collaborative writing can help students advance within their zone of proximal development (ZPD). ZPD is defined as the gap between what a learner can accomplish alone and in cooperation with others who are more skilled or experienced.

In response to the collaborative potential of Web 2.0 tools, practices that encourage collaboration among learners are being increasingly advocated in second language classrooms. The research on collaborative writing suggests that collaboration leads to an increase in the complexity of written texts (Sotillo, 2000). Consequently, the complexity of the final product and the higher quality of the joint work in collaborative writing projects have been known as sources of student motivation (Swain \& Lapkin, 1998). The final products of collaborative writings have a better sense of audience (Leki, 1993) and are enriched with knowledge (Donato, 1994). Furthermore, the writing process itself, which includes planning, co-creating written work, peer-reviewing and co-editing, can engage learners in becoming more active and responsible (Scardamalia, 2002).

Swain and Lapkin (1998) find that attention to discourse structures as well as grammar and vocabulary usage were the discriminating features of collaboratively written texts. Focusing on the importance of social interaction, Hirvela (1999) notes the opportunities that collaborative writing brings about for students to write as part of a community and to rely on each other for support and guidance. In order to increase collaboration, Ware (2004) suggests flexibility in grading collaborative written works to avoid establishing a sense of competition and to encourage support and guidance. 


\section{Using Wikis for Collaborative Writing}

Computer Mediated Communication (CMC) provides a social interactive environment appropriate for collaborative learning that encourages students' responsibility toward learning and allows students to exercise control over tasks (Chao \& Lo, 2009). The affordances of CMC allow learners to discuss their ideas collaboratively via tools such as forums, email, wikis and conferencing applications. These tools are claimed to "stretch the input and output limits of FL classrooms" (Ortega, 2007, p. 198).

One of the well-known CMC open sources, the wiki (Cunningham, 1998), provides a web space for social interaction and collaboration (Godwin-Jones, 2003). It provides learners with a tool to collaboratively create, transform, and erase their work through the built-in affordances. The wiki tracking system, which discriminates wiki from other CMC tools, allows teachers to follow student-writers' collaborative processes by examining the changes. Flexibility of the wiki promotes the shaping and sharing of knowledge when working collaboratively. Also, the potential of the wiki for increasing collaboration has made it a useful tool for educational purposes. Though wiki technology has a relatively short history, it has already found its place within the language teaching profession.

Many researchers have studied the potentials of wikis in foreign language education (e.g. Kessler, 2009; Kessler \& Bikowski, 2010; Oskoz \& Elola, 2010). In order to increase the collaborative value of a wiki, Oskoz and Elola (2010) suggest adding synchronous web-based text and audio applications to further increase the level of interaction and accountability of the participants. Kessler (2009) studied student-initiated attention to form in a wiki-based collaborative writing and found that students are successful in using wikis autonomously. In his study however, the final product represented less student-initiated attention to form, indicating that even with many-to-many collaborative writing, grammatical accuracy does not necessarily increase. Nevertheless, when used as a tool for collaborative writing, wikis are useful in the redefinition of authorship from an author-centric perspective to a more collaborative stand (Hunter, 2011).

\section{METHOD}

\section{Design}

The current study adheres to the mixed-method paradigm, benefitting from both qualitative and quantitative approaches. The quantitative part of the study included a thorough directed content analysis over the final collaborative writing to find the alterations made by student-writers. The reason for using directed content analysis was that the codes extracted from the final product were formed based on Kessler and Bikowski's (2010) study. Although there were slight differences in the coding system, the core elements were nearly alike. Also, for the qualitative part, interviews were carried out which were aimed at studying the role of teacher in autonomous collaborative writing. A semi-structured interview conducted at the end of the semester sought to uncover learners' perception about the role of teacher in an autonomous writing project.

\section{Participants}

The current study analyzes the data collected from 18 upper-intermediate Iranian EFL learners enrolled in online synchronous general English courses with a specific focus on writing skill. The participants were female and male adults, with an age range of 18 to 30, who were participating in online English courses offered by E-Zaban virtual language institution from different cities of Iran. All the participants had prior experience of learning English language online for almost two years. The current course was delivered through a Moodle-based course management system with additional features of Adobe Acrobat Connect and synchronous video and voice interaction. Students were required to participate twice a week in live video sessions to receive new lessons and interact with the instructor and classmates. They were also expected to $\log$ into the system regularly to access the materials uploaded by the instructor. The participants were experienced in using the course management system for general English language course. However, due to the focus of the course which was writing skill, the wiki was introduced as an educational technology to assist collaborative learning. Finally, the learners were required to participate in a wiki-based collaborative writing to complete a written project. The wiki allowed students to collaboratively build, revise and complete their writing projects within an eight-week long course. 


\section{Instrumentation}

\section{Wiki}

Wikis are websites created by individuals and edited collaboratively by communities of users. What makes wikis an appropriate educational tool is the relative ease with which a group of people can collaborate together to edit the content of the website. Also, the possibility of tracking back modifications through the "history" feature and the availability of the "commenting" feature on all pages makes the wiki an appropriate educational tool to practice collaboration. According to the literature (Chao \& Lo, 2011; Peled, Bar-Shalom \& Sharon, 2012; Wichmann \& Rummel, 2013) there are three potential advantages within Wikis which make them proper tools for educational purposes. Firstly, wikis support multiple users to create and modify articles, texts, or documents. Secondly, the History of a wiki keeps track of all edits, by means of color coding, allowing users to trace all revisions being made. And thirdly, the discussion page enables asynchronous written communication between users by providing explanations and posting comments on various issues related to the wiki. Among the plethora of wiki tools, the current study chose Wikispaces (www.wikispaces.com), which is a free educational wiki service provider. The current wiki was initially created by the instructor, but the writing process, including all stages of writing, were initiated and completed by the learners.

\section{Wiki-based Collaborative Writing}

Underpinned by Vygotsky's sociocultural learning theory, collaborative writing highlights the importance of collaboration among participants for optimum benefits from learning. The theory involves the essentials of a collaborative writing project known as language, social interaction, and Zone of Proximal Development (ZPD). ZPD is defined as the "distance between the actual developmental level determined by independent problem-solving, and the level of potential development as determined through problem solving under adult guidance or in collaboration with more capable peers" (Vygotsky,1978, p. 86). Hence, the affordances of a wiki allow these three elements to coexist enabling wiki users to reach their potential developmental levels by social interaction during the projects. Thus, interactions between students and teacher are mutually supported to reach the potential of ZPD (Mindel \& Verma, 2006).

Apart from the above-mentioned possibilities, the Wiki paves the way for collaborative writing projects by allowing users to edit and revise their contributions to the wiki (Chao \& Lo, 2011). Alterations and changes are also made directly to the text being written. Moreover, argumentations and critical reflections accompanying the revisions may arise in the discussion page.

\section{Interview}

Interview was the method of data collection for the second research question. A semi-structured interview of the teacher-researcher with the participants in the writing course was conducted in the virtual classroom at the end of the writing course, as well as through Skype for some complementary questions. The questions that revolved around the teacher's role in a collaborative autonomous writing were as follow:

1. Was the teacher's presence helpful in completion of collaborative writing task? (If yes how)

2. Could you complete the task without teacher's intervention?

The second complimentary interview included one question posed as: "In your opinion, which roles of the teacher [facilitator, counsellor, and resource] can help you the most in the completion of an autonomous collaborative writing project?". The interview was done separately for each individual through Skype. The complimentary interview was done through Skype and English was the language of the interview. Throughout the interview, each student had time to think and answer the interview questions, which lasted around 20 minutes. Students' responses were recorded for later transcription and analysis.

The data from semi-structured interview which allowed learners to reflect on the interview questions went through a manual thematic analysis, and the extracted themes and the related excerpts were categorized for the second research question. 


\section{Procedure}

The wiki, as the core element of writing for the course, was created, developed, and revised during 14 sessions of the writing course. The teacher-researcher (i.e. the first researcher) introduced the concept of the wiki by showing screenshots taken from different sections of a wiki and elaborating on the ways wikis function. Later we created a wiki and introduced it to the learners who were given time to explore and send posts to practice writing in the new medium. The participants in the writing course had 14 sessions to build, edit, and reflect on the collaboratively produced texts. The subject of writing was introduced by the teacher based on prior consultation with the learners and one student voluntarily initiated writing the introductory paragraph. Each student was responsible for developing collaborative writing by adding at least one paragraph to the existing paragraphs and making two revisions. The revisions were done on a weekly basis, though some students contributed to the writing project more than once a week.

Mainly, student-writers were responsible for adding a paragraph each week and editing the text for formand meaning-related errors. Students were regularly reminded by the teacher to consider coherence and cohesion in the changes they made to the text. The teacher-researcher also cooperated in the writing process by reflecting on errors as well as giving feedback regarding cohesion and coherence of the text in a section entitled Discuss. Ultimately, the final text which was around 2700 words was analyzed to find the number and types of alterations made by student-writers. The alterations were then evaluated based on the principles extracted from the collaborative autonomous learning framework presented by Kessler and Bikowski (2010). Those alterations which were not easily categorizes as an autonomous alterations were identified during the analysis stage and after discussing with the student-writer in charge were sent to the right category of autonomous alterations.

The track-back (i.e. page history) affordance of the wiki also provided a detailed map of the alterations that students had made to the wiki. Thus, to keep up with the changes, the teacher-researcher created a weekly report of the number and types of alterations (based on the principles introduced by Kessler \& Bikowski (2010) for each learner. These reports went through a detailed manual analysis to find out the types of alterations made by each learner. In case of vague alterations, clarifications were requested from the studentwriters which yielded the data for the first research question.

Also, during the coding process, two other researchers were asked to code the alterations for the purpose of cross-checking (Guest et al., 2012). Based on the intercoder agreement results, there was $80 \%$ agreement among three coders which indicated an acceptable estimate of reliability.

Moreover, for securing the study from validity threats, multiple validity strategies (Cresswell, 2014) were applied to the process of data collection and final analysis. As the first step, sources of possible bias were determined during the interview stage. Consequently, the teacher researcher elaborated on them prior to the interview and informed the learners of the value of responses for the purpose of research.

Moreover, after the collection of research data through content analysis and interview, an external auditor was required to provide an objective assessment of the project. Based on the judgment of the external auditor, the process of data collection and transcription was in line with the purpose of research which confirmed the validity of the study.

\section{RESULTS}

The first research question of the study sought to investigate the patterns of Iranian EFL learners' autonomy in a collaborative attempt to accomplish a wiki-based writing project. In estimating the amount of autonomous behavior based on Kessler and Bikowski's (2010) principles, student-made changes to the wiki were tracked and the alterations that were considered autonomous were counted. Kessler and Bikowski maintain that autonomous learners manifest an ability to use language to independently contribute personal meanings as a collaborative member of a group, and show tendency to use appropriate strategies for communicating interdependently in the social structure of their groups. Therefore, autonomous alterations were considered to be those that were done independently by the student-writers and were meaningful (i.e. made sense when applied to the previous text); showed interaction with teacher, peer, computer or material; and led toward the learning objectives. Overall, student-writers manifested a considerable amount of autonomy 
based on this criterion. Table 1 shows the total number of alterations made by student-writers, and Table 2 demonstrates the number and type of autonomous alterations.

Table 1. The number of alterations made by students

\begin{tabular}{lc}
\hline Number of alterations & Number of students \\
\hline 4 or more & 7 \\
2 or 3 & 9 \\
1 & 1 \\
\hline
\end{tabular}

As Table 1 shows, seven students contributed to the development of the text more than four times, among which, one student had the highest number of alterations to the wiki (i.e. seven alterations) and another did not participate in the writing project at all.

An analysis of the final product represented various kinds of changes. These changes included adding new information (from a single sentence to a paragraph); deleting existing information; correction of information (correction due to wrong structure or meaning); clarification; synthesis; reflection; and cosmetic change. Adding new information and deleting the unrelated parts helped the group to create the foundations of the text whereas, clarification and synthesis were aimed at enhancing the quality of the text and adding artistic effects to the writing. Student comments on some parts of the text were also used for the purpose of elaboration. Alterations known as cosmetic change occurred when a student made a change to the appearance of the wiki. Changes in the style, background, and font color were considered cosmetic and as they did not contribute to the meaning or structure of the text, they were omitted from the list of autonomous alterations. Finally, in the case of alterations which could not be easily understood or classified, elaborations were requested from the student-writer responsible for the change. Table 2 presents the types and numbers of autonomous alterations.

Table 2. The number of autonomous alterations

\begin{tabular}{ll}
\hline Type of autonomous alterations & Number of alterations \\
\hline Adding new information & 22 \\
Deleting existing information & 10 \\
Correction of information & 9 \\
Clarification & 6 \\
Synthesis & 2 \\
Reflection & 9 \\
\hline
\end{tabular}

As clarified earlier, based on Kessler and Bikowski's study (2010), only the alterations which manifested interaction with text, peer, technology, and teacher within the social structure of a group were considered autonomous. Furthermore, autonomous alterations resulted in the improvement of the text in general rather than merely fulfilling the course requirement. Thus, for instance, two of the deletion instances did not meet autonomous alteration criteria and were not considered as manifesting autonomous behavior. An example of a collaborative autonomous deletion can be found in the following excerpt from the wiki:

Technology brings with itself to us freedom to choose among many ways to present our research findings to the interested audience. (P. Maleki, February, 2016)

The underlined words were deleted by one of the learners. It is apparent that the deleted part was a redundant part of the sentence, omitted for the sake of clarity. On the other hand, there were some instances of deletion that did not seem to be collaborative as they did not show interaction with peers and the final goal. These alterations appeared to violate the interdependence maxim of autonomous alterations as they did not contribute to the improvement of the text in constructive ways. The following excerpt from the wiki shows how a deletion was considered a non-autonomous act. 
Before bringing technology to elementary schools, teachers should be trained about using those technologies for educational purposes. One problem that arises when this principle is violated is budget problem. Budget problem refers to spending the money which is for the school to the facilities that are not going to be useful at that school. (M. Assari, January 2016)

Though the underlined part of the collaborative essay was deleted, there was no attempt at revising the text after deletion or clarifying the reason for the deletion. When the student-writer was asked for the reason, reducing the length of the paragraph was the reason for deleting the underlined part. The analysis of the essay, however, proved that the length of the paragraph was acceptable and the deletion had resulted in the violation of the maxim of interaction. Moreover, the writer of the paragraph was annoyed by the deletion and commented: "Why did you wrongly delete my paragraph?" (N. Aazadeh, February, 2016)

The second research question sought to uncover the students' perceptions about the effectiveness of teacher intervention in a collaborative autonomous online environment. At the initial stages of collaborative writing, the teacher's intervention in the form of comments was more frequent to help learners with technical and content knowledge. As the project processed, the teachers' comments were less frequent and mainly addressed the students' questions and problems. Eighteen students responded to the interview questions about the role of the teacher in an autonomous collaborative writing project. A considerable number of the students (i.e. fourteen out of eighteen learners) found teacher intervention necessary for increasing learners' motivation and the correction of language-related errors.

Feeling that the teacher was reading our text very quickly, made me write better paragraphs every day. She always encouraged us with kind words. (B. Javidmajd, February, 2016)

If the teacher was not there we couldn't continue, as she forced us and also helped us with motivating words. She mentioned the right points, that none of us thought could be mistakes. (M. Taher, January, 2016)

If the teacher didn't log in, we couldn't complete it like our weblogs. We students always need a power. And also our teacher is very careful with mistakes, she controls them very well. (M. Assari, February, 2016)

The results of the interview revealed that the learners needed the teacher as a source of motivation (and even force!) for completing the project. Teacher intervention was also generally considered helpful and motivating. Yet, there were some students who appeared to rely on their peers rather than the teacher.

My classmates were very helpful in teaching me to correct my mistakes, we could progress without teacher even; we were dependent on each other more than teacher. (N. Aazadeh, March, 2016)

Teacher is very good in the class but neutral in wiki writing. Sometimes her comments were good but not very important. (G. Fatemi, March, 2016)

During the second interview that aimed at studying the teacher's role in more depth, the question posed was: In your opinion, which roles of the teacher [facilitator, counsellor, and resource] can help you the most in the completion of an autonomous collaborative writing project such as a wiki writing? Elaborate. (It is worth noting that the above roles were first explained to the participants.)

Eight out of eleven learners who took part in the interview found the role of the teacher as a resource to be the most prominent. As it is clear in the quotations below, learners stated that it is possible to move forward without a counsellor to some extent, but there is always a need for a knowledge provider for accurate and reliable learning material. Moreover, three students highlighted the role of teacher as a facilitator or provider of motivation throughout their learning paths. The teacher as facilitator also had a strong presence at the beginning of the project to make students acquainted to the new writing environment.

It is possible to learn more about wiki from my classmates, but the comments that the teacher provides for the mistakes are all new. (M. Assari, May, 2016) 
The most important comments are writing comments... the teacher was a knowledge provider. (A. Aali, May, 2016)

She motivated us, but giving knowledge is more important than motivation. It is about three years that we are learning English online, me and some of my classmates..., sometimes some tools are new, but finally we discover how to work with them. But we always need our teacher to help us with the right points. (N. Aazadeh, May, 2016)

Overall, the interviews revealed that learners preferred the teacher to be a source of knowledge and motivation and believed that teachers' monitoring motivated them to move forward. Furthermore, teacher knowledge was considered a reliable source and the learners wanted their teacher for accurate error feedback.

\section{DISCUSSION AND CONCLUSION}

The first research question studied the patterns of Iranian EFL learners' autonomy in a collaborative attempt to accomplish a wiki-based writing project. Based on the number of autonomous alterations, the results suggest that students manifested autonomy in the writing process. Autonomous alterations in the current study included adding new information; deleting existing information; correction of information; clarification; synthesis; and reflection. However, meaning related changes (MRCs) manifested a slight difference compared to Kessler and Bikowski's (2010) study that included MRCs such as: adding new information; deleting information; clarification/elaboration of information; synthesis of information and addition of URL links. An outstanding feature of the current study was the frequent occurrence of peer correction with regard to content and form as a dominant form of collaboration. Furthermore, learners in the current study did not rely on hyperlinks as a link to the source of information. Instead they provided related information to their peers through comments. In the same vein, researchers (e.g., Donato, 1988; Storch, 2002; Swain \& Lapkin, 1998) have shown that throughout the process of co-authoring a text, lexical aspects as well as discourse is improved along with grammatical accuracy.

A detailed analysis of the alterations to the text, which started from writing the first paragraph and ended with a complete essay with 2700 words, revealed that all the alterations were aimed at a shared final goal which was creating a coherent and united essay. Learners' collaboration and the interaction between the learners; teacher; peers; computer; material; and the learning goal resulted in a final product which as a process encouraged learners' autonomous collaborative contribution.

The findings were also supported by the principles of constructivism. Schwienhorst (2012) believes that for a second language learning to be productive, it should follow a Vygotskyan approach encouraging interaction and collaboration (Parker \& Chao, 2007). Although, wikis are not known to be inherently collaborative (Judd, Kennedy\& Cropper, 2010) the features they possess can facilitate knowledge building among peers within a community rather than individually. Wikis facilitate interaction and collaboration with peers and teachers which leads to shaping meaning and constructing knowledge constructed (Higgs \& McCarthy, 2005). In the current study, the number of autonomous alterations to the wiki demonstrates that wikis promote autonomous collaboration in a writing task through providing the student-writers with the opportunity to complete a shared writing project. The number of interactions between peers and teacher in the form of reflections and commenting could be considered as an instance of scaffolding to reach a shared goal. Although there were some coherence and cohesion-related problems with the final text, writing in a wiki was a successful experience due to the collaboration of many writers and the length of text and experiencing interdependence in reaching a shared goal collaboratively. In fact, preparation to reach a common goal help student to coordinate their efforts systematically (Wichmann \& Rummel, 2013).

In addition, wikis were found helpful in encouraging learners to write for a global audience and communicate with peers through the collaborative writing process. Learners' communications with peers in the form of comments and reflections added to the precision of the final product. Moreover, student-writers showed solidarity with peers through commenting and subsequent revising, which suggest a positive role of wikis in fostering collaborative learner autonomy in writing. In fact, the premise that wikis are built for collaboration and that they encourage interdependence, makes them appropriate for collaborative autonomous projects. 
However, the mere presence of wikis does not guarantee the success of a collaborative project aiming at encouraging learner autonomy. Indeed, as Grant (2009) indicates, to consider technology a solution for collaboration is in fact underestimating the nature of collaboration. Collaboration and autonomy are more of a cultural issue rather than mere technological, however, technologies such as wikis have the potential to assist the process of collaboration. For a collaborative project to be successful in encouraging learner autonomy, there should exist interaction between one's independent work; the computer; material; peers; teacher, and the learning objectives (Kessler \& Bikowski, 2010). Thus, extending wiki for a collaborative writing project necessitates a constant supervision to stimulate peers' contribution and observe content and technical issues. Therefore, for a deeper study of the nature of interaction between learner or teacher or what was called teacher intervention in this study, we investigated the most beneficial teacher role from the students' point of view.

The second research question sought to uncover the students' perceptions about the effectiveness of teacher intervention on learners' autonomous behaviors in a collaborative online environment. A considerable number of learners (i.e. fourteen out of eighteen) found teacher intervention as helpful and a source of motivation in an online collaborative writing project. Learners preferred the teacher to monitor their progress, even in a student-initiated task. This preference may be in part due to the fact that Iranian learners are more accustomed to a teacher-centered educational system. In any case, however, the results of the current study indicated a need for teacher intervention among student-writers in an online autonomous collaborative writing project. The findings are contrary to the common beliefs about the limited need of autonomous learners for teacher. The need may have been strengthened by the fact that the learners were experiencing learning in a technology-rich environment, replete with new challenges. Additionally, the experience of writing for many readers was a challenge, which possibly made them rely more on teacher corrections and comments.

According to the results taken from the interviews, learners preferred the teacher to take on the roles of motivator and knowledge provider simultaneously; yet they were not fully dependent on their teacher through the course of writing. Autonomous learners need psycho-social support from the teacher, which includes support for motivating learners and raising their awareness of the learning process (Voller, 1997). This means that they need to practice interdependence rather than full independence in learning. Teachers should also balance control and freedom in terms of responsibility and autonomy in their teaching. In other words, interdependence exists not only among peers in autonomous collaborative writing, but also the students and the teacher are committed to the completion of the project interdependently. In the same vein, Kessler (2009) believes that a "limited amount of teacher intervention, or some external incentive, would encourage more attention to issues of accuracy" (p. 90) or more generally a successful_collaborative writing.

It is worth mentioning that the concept of interdependence which involves "cooperating with others and solving conflicts in a constructive way" (Kohonen, 1992, p.19) relies to a great extent on technology in modern educational settings. Including technology in teaching brings about motivation to autonomous learners. Although, some learners find the experience frustrating due to the complexities of using technology. Moreover, current technologies provide a wide access to tools and applications for the writing skill. As an instance, wikis are known to increase computer-supported collaborative learning (Augar, Raitman \& Zhou, 2004) through peer interaction and group work. Such a power in wikis facilitates sharing among a community of learners (Parker \& Chao, 2007) in comparison to a face-to-face learning environment which often confines collaborative writing to pair work (Kessler, Bikoeski \& Boggs, 2012).

\section{Limitations}

The most obvious limitation to the current study is the issue of external validity. As the results were collected from a small convenience sample, they may only represent small groups. Future studies can work with larger population and various age ranges to confirm the issue and until then, the results should be taken with caution.

Online collaborative tools make it possible for students to practice autonomy in flexible learning environments, through interdependence which entails cooperating with others toward solving conflicts in a constructive way (Kohonen, 1992). Autonomy and interdependence seem to have a reciprocal relationship 
and interaction lies at the heart of this relationship. In technology-rich learning environments, optimal interaction between the tool, teacher, peers and materials should take place and lead toward final objectives. The vastness and novelty of educational technologies impose some limitations to the studies done in this field. As an instance, the current study did not investigate the invisible or lurking students and the reason they did not show up regularly in collaborative completion of the text. These students were not motivated to take part in building the text and were passive listeners with a few interactions. More studies should focus on studying levels of autonomy among lurking students and whether they could gain the principles of autonomy by being a passive participant in the online course. Another set of limitations stemmed out of the internet and the nature of online courses. Learners' regular disconnections and other technical problems recurrently resulted in students' missing the discussions parts of instruction. It is suggested that future researchers take the internet problems into consideration and find alternative ways to deal with the problem.

\section{BIODATA and CONTACT ADDRESSES of AUTHORS}

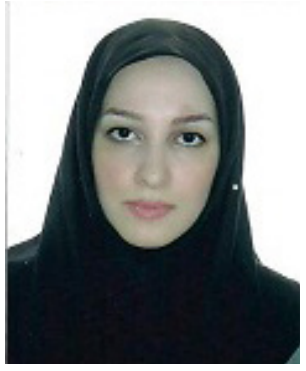

Dr. Shirin SADAGHIAN completed her Ph.D. at Alzahra University, Tehran, Iran, focusing on the issue of language learner autonomy in online education. Her field of interest includes Computer-assisted Language Learning, Self-Directed learning, and Language Learner Autonomy. She is currently teaching at Azerbaijan Shahid-Madani University, Tabriz, Iran.

Shirin SADAGHIAN

Address: Alzahra University, Tehran, Iran.

Phone: 00989144006851

Email: Shirin_Sadaghian@yahoo.com

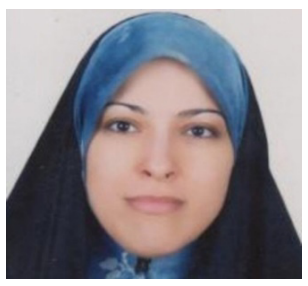

Dr. Susan MARANDI is an associate professor of Teaching English as a Foreign Language (TEFL) and the head of English Language department at Alzahra University, Tehran, Iran. Her current interests are Computer Assisted Language Learning (CALL), Language Assessment, and Localized Practices in Language Teaching. She has published in many scholarly journals and is well-known for pioneering research and projects on online language education in Iran.

Susan MARANDI

Faculty of Literature

Address: Department of Languages, Alzahra University, Tehran, Iran.

Phone: (+98-21) 88041461

Email: susanmarandi@alzahra.ac.ir 


\section{REFERENCES}

Augar, N., Raitman, R., \& Zhou, W. (2004, January). Teaching and learning online with wikis. In Beyond the comfort zone: proceedings of the 21st ASCILITE Conference, Perth, 5-8 December (pp. 95104). ASCILITE.

Benson, P. (2001). Teaching and researching autonomy in language learning. Harlow, England: Longman.

Benson, P. (2007). Autonomy in language teaching and learning. Language Teaching, 40(01), 21-40. Doi: $10.1017 / \mathrm{s} 0261444806003958$

Chan, V. (2001). Readiness for learner autonomy: What do our learners tell us? Teaching in Higher Education, 6(4), 505-518. Doi:10.1080/13562510120078045

Chao, Y. C. J., \& Lo, H. C. (2011). Students' perceptions of Wiki-based collaborative writing for learners of English as a foreign language. Interactive Learning Environments, 19(4), 395-411. Doi:10.1080/10494820903298662

Chesher, C. (2005). Blogs and the crisis of authorship. Blog Talk Downunder. Available at: http://www. incsub.org/blogtalk.

Creswell, J. W. (2014). A concise introduction to mixed methods research. SAGE publications.

Cunningham, W. (1998). What gets protected in a (S)Wiki [On-line]. Available at: http://pbl.cc.gatech. $\mathrm{edu} / \mathrm{myswiki} / 7$.

Donato, R. (1994). Collective scaffolding in second language learning. In J. Lantolf \& G. Appel (Eds.), Vygotskian approaches to second language research. Cambridge: Cambridge University Press.

Guest, G., MacQueen, K. M., \& Namey, E. E. (2012). Introduction to applied thematic analysis. Applied thematic analysis, $3,20$.

Grant, L. (2009). 'I don't' care do our own page!' A case study of using wikis for collaborative work in a UK secondary school. Learning, Media, and Technology, 34(2), 105-117.

Godwin-Jones, R. (2003). Emerging technologies. Language Learning \& Technology, 7(2), 12-16.

Healey, D. (2007). Theory and research: Autonomy and language learning. In J. Egbert \& E. Hanson-Smith (Eds.), CALL environments: Research, practice and critical issues (pp. 377-389). Alexandria, VA: TESOL.

Higgs, B., \& McCarthy, M. (2005). Active learning-from lecture theatre to field-work. Emerging issues in the practice of university learning and teaching, 37-44

Hirvela, A. (1999). Collaborative writing instruction and communities of readers and writers. TESOL Journal, 8(2), 7-12.

Holec, H. (1985) On autonomy: some elementary concepts. In R. Philip (Ed.), Discourse and Learning (pp. 173-190). Longman.

Hunter, R. (2011). Erasing "property lines": A collaborative notion of authorship and textual ownership on a fan wiki. Computers and Composition: An International Journal for Teachers of Writing, 28(1), 40-56. Doi: 10.1016/j.compcom.2010.12.004

Judd, T., Kennedy, G., \& Cropper, S. (2010). Using wikis for collaborative learning: Assessing collaboration through contribution. Australasian Journal of Educational Technology, 26(3), 341-354.

Kessler, G. (2009). Student-initiated attention to form in wiki-based collaborative writing. Language Learning \& Technology, 13(1), 79-95.

Kessler, G., \& Bikowski, D. (2010). Developing collaborative autonomous learning abilities in computer mediated language learning: Attention to meaning among students in wiki space. Computer Assisted Language Learning, 23(1), 41-58. Doi:10.1080/09588220903467335

Kessler, G., Bikowski, D., \& Boggs, J. (2012). Collaborative writing among second language learners in academic web-based projects. Language Learning \& Technology, 16(1), 91-109. 
Kohonen, V. (1992). Experiential language learning: Second language learning as cooperative learner education. In D. Nunan (Ed.), Collaborative language learning and teaching (pp. 14-39). Cambridge: Cambridge University Press.

Leki, I. (1993). Reciprocal themes in reading and writing. In J. Carson, \& I. Leki (Eds.), Reading in the composition classroom: second language perspectives (pp. 9-33). Boston: Heinle \& Heinle.

Levy, M., \& Hubbard, P. (2005). Why call call “CALL”? Computer Assisted Language Learning, 18(3), 143149. Doi: $10.1080 / 09588220500208884$

Levy, M. (1997). Computer-Assisted Language Learning. Oxford University Press, New York.

Little, D. (1995). Learning as dialogue: The dependence of learner autonomy on teacher autonomy. System, 23(2), 175-181. Doi:10.1016/0346-251x(95)00006-6

Little, D. (1996). Freedom to learn and compulsion to interact: Promoting learner autonomy through the use of information systems and information technologies. In R. Pemberton, E. S. L. Li, W. W. F. Or, \& H. D. Pierson (Eds.), Taking control: Autonomy in language learning (pp. 203-218). Hong Kong: Hong Kong University Press.

Littlewood, W. (1996). "Autonomy": An anatomy and a framework. System, 24(4), 427-435. Doi:10.1016/ s0346-251x(96)00039-5

Luke, C. L. (2006). Fostering learner autonomy in a technology-enhanced, inquiry-based foreign language classroom. Foreign Language Annals, 39 (1), 71-86. Doi:10.1111/j.1944-9720.2006.tb02250.x

Mindel, J. L., \& Verma, S. (2006). Wikis for teaching and learning. Communications of the Association for Information Systems, 18(1), 2-38.

Ortega, L. (2007). Meaningful L2 practice in foreign language classrooms: A cognitive-interactionist SLA perspective. In R. M. DeKeyser (Ed.), Practice in second language: Perspectives from Applied Linguistics and Cognitive Psychology (pp. 180-207). NewYork, NY: Cambridge University Press.

Oskoz, A., \& Elola, I. (2010). Meeting at the wiki: The new arena for collaborative writing in foreign language courses. In M. Lee \& C. McLaughlin (Eds.), Web 2.0-based E-learning: Applying social informatics for tertiary teaching (pp. 209-227). Hershey, PA: IGI Global.

Parker, K. R., \& Chao, J. T. (2007). Wiki as a teaching tool. Interdisciplinary Journal of Knowledge and Learning Objects, 3, 57-72.

Peled, Y., Bar-Shalom, O., \& Sharon, R. (2012). Characterisation of pre-service teachers' attitude to feedback in a wiki-environment framework. Interactive Learning Environments. http://dx.doi.org/10.108 0/10494820.2012.731002.

Reinders, H. \& Hubbard, P. (2012). 'CALL and autonomy. Affordances and constraints'. In: Thomas, M., Reinders, H., \& Warschauer, M. (Eds.), Contemporary CALL. New York: Continuum.

Scardamalia, M. (2002). Collective cognitive responsibility for the advancement of knowledge. In B. Jones (Ed.), Liberal education in a knowledge society (pp. 67-98). Chicago: Open Court.

Schwienhorst, K. (2003). Learner autonomy and tandem learning: Putting principles into practice in synchronous and asynchronous telecommunications environments. Computer Assisted Language Learning, 16(5), 427-443. Doi:10.1076/call.16.5.427.29484

Schwienhorst, K. (2008). Learner autonomy and virtual environments in CALL. Routledge studies in computer assisted language learning. London: Routledge.

Schwienhorst, K. (2012). Learner autonomy and CALL environments. Routledge.

Sotillo, S. M. (2000). Discourse functions and syntactic complexity in synchronous and asynchronous communication. Language Learning \& Technology, 4(1), 82-119.

Storch, N. (2002). Patterns of interaction in ESL pair work. Language Learning, 52(1), 119-158. Doi: https:10.1111/1467-9922.00179 
Swain, M., \& Lapkin, S. (1998). Interaction and second language learning: Two adolescent French immersion students working together. The Modern Language Journal, 82(3), 320-337. Doi:10.1111/j.1540-4781.1998.tb01209.x

Voller, P. (1997). Does the teacher have a role in autonomous learning? In P. Benson \& P. Voller (Eds.), Autonomy and Independence in Language Learning (pp. 98-113). Longman.

Vygotsky, L. (1978). Interaction between learning and development. Readings on the Development of Children, 23(3), 34-41.

Vygotsky, L. S. (1978). Mind and society: The development of higher mental processes. Cambridge: MA, Harvard University Press.

Ware, P.D. (2004). Confidence and competition online: ESL student perspectives on web-based discussions in the classroom. Computers and Composition, 21(4), 451-468. Doi: 10.1016/j. compcom.2004.08.004

Warschauer, M., Turbee, L., \& Roberts, B. (1996). Computer learning networks and student empowerment. System, 24(1), 1-14. Doi:10.1016/0346-251x(95)00049-p

Wichmann, A., \& Rummel, N. (2013). Improving revision in wiki-based writing: Coordination pays off. Computers \& Education, 62, 262-270. 